\title{
Quitosana associada com extratos vegetais no controle pós-colheita de antracnose em mamão 'formosa'
}

\author{
Jaqueline Clara Longo Casemiro $^{1 *}$, Lilian Maria Arruda Bacchi ${ }^{2}$, Héber Ferreira dos Reis ${ }^{3}$, Walber Luiz Gavassoni ${ }^{2}$
}

\begin{abstract}
${ }^{1}$ Aluna de pós-graduação em Agromomia da UFGD/Dourados, Rod. Dourados-Itahum Km 12, Dourados, MS, Brasil - CEP $39870-900 ;{ }^{2}$ Professores Associados da FCA, UFGD/Dourados, Rod. Dourados-Itahum Km 12, Dourados, MS, Brasil - CEP 39870-900; ${ }^{3}$ Pesquisador da AGRAER/MS, R. João Fagundes de Menezes, 135 - Centro, Dourados, MS, Brasil, CEP 79840-000. *Parte da dissertação de mestrado do primeiro autor. Autor para correspondência: Jaqueline Clara Longo Casemiro (jaquecasemiro@hotmail.com)
\end{abstract}

Data de chegada: 24/11/2016. Aceito para publicação em: 24/08/2017.

$10.1590 / 0100-5405 / 172445$

\section{RESUMO}

Casemiro, J.C.L.; Bacchi, L.M.A.; Reis, H.F.; Gavassoni, W.L. Quitosana associada com extratos vegetais no controle pós-colheita de antracnose em mamão 'formosa'. Summa Phytopathologica, v.45, n.1, p.64-69, 2019.

O uso excessivo de produtos químicos na cultura do mamão (Carica papaya) coloca em risco a eficácia de fungicidas, em razão dos problemas de resistência dos patógenos a esses produtos, além da possibilidade de resíduos tóxicos colocarem em risco a saúde humana e o ambiente. Diante disto, o presente trabalho teve por objetivo avaliar a eficácia de produtos naturais no controle de Colletotrichum gloeosporioides, in vitro e in vivo. No ensaio in vitro, avaliou-se os extratos aquosos de cravo-da-índia (Syzygium aromaticum) e canela (Cinnamomum zeylanicum) a $15 \%$, quitosana $4 \%$, isoladamente, a associação desses extratos de plantas com quitosana a $4 \% \mathrm{e}$, também, o fungicida procloraz (100 $\left.\mathrm{mg} \mathrm{L}^{-1}\right)$, adicionados ao meio de cultura BDA, quanto ao efeito sobre o crescimento micelial do fungo, mantendo-se uma testemunha sem adição de produtos. O tratamento com o extrato aquoso de cravo-da-índia a $15 \%$ e sua associação com a quitosana, inibiram o crescimento micelial. A associação de quitosana com o extrato aquoso de canela foi mais eficaz na redução do crescimento micelial do que os dois isoladamente. No ensaio in vivo, os frutos de mamoeiro Formosa foram submetidos aos tratamentos por imersão: 1 - Testemunha (água destilada); 2 Testemunha - fungicida procloraz (Sportak ${ }^{\circledR}$ 450 EC) na concentração de $0,75 \mathrm{~mL} \mathrm{~L}^{-1} ; 3$ - quitosana (4\%); 4 extrato aquoso de cravo-da-índia (10\%); 5 - extrato aquoso de canela (30\%); 6- extrato aquoso de cravo da índia (10\%) + quitosana (4\%); 7 - extrato aquoso de canela $(30 \%)+$ quitosana (4\%). Após $24 \mathrm{~h}$, os frutos foram inoculados com C. gloeosporioides e avaliados quanto à severidade da doença a cada dois dias. Observou-se, que apenas na terceira avaliação, os tratamentos com fungicida e extrato aquoso de canela a $30 \%$ associado à quitosana a $4 \%$ reduziram a severidade da doença, comparados à testemunha. Avaliando-se a área abaixo da curva de progresso da doença, observou-se que o tratamento com extrato aquoso de cravo também foi eficaz em reduzir a severidade da antracnose nos frutos.

Palavras-chave: Carica papaya L., Colletotrichum gloeosporioides, controle alternativo.

\begin{abstract}
Casemiro, J.C.L.; Bacchi, L.M.A.; Reis, H.F.; Gavassoni, W.L. Chitosan associated with plant extracts in the post-harvest control of anthracnose in papaya 'formosa'. Summa Phytopathologica, v.45, n.1, p.64-69, 2019.

Excessive use of chemicals in papaya (Carica papaya L.) crops puts the efficacy of fungicides at risk because of the resistance problems of pathogens to these products, besides the possibility of toxic residues endangering the human health and the environment. Therefore, the present study aimed to evaluate the efficacy of natural products in controlling Colletotrichum gloeosporioides in vitro and in vivo. In the in vitro assay, the evaluated products were aqueous extracts of clove (Syzygium aromaticum) and cinnamon (Cinnamomum zeylanicum) at $1.5 \%$ and chitosan at $4 \%$, separately, and the association of these plant extracts with $4 \%$ chitosan, as well as the fungicide prochloraz $\left(100 \mathrm{mg} \mathrm{L}^{-1}\right)$, added to PDA culture medium; they were evaluated for their effect on the mycelial growth of the fungus, maintaining a control without addition of products. The treatment with aqueous extract of clove at $15 \%$ and its association with chitosan inhibited mycelial growth. Association of chitosan

with aqueous extract of cinnamon was more effective in reducing mycelial growth than the two products used separately. In the in vivo test, papaya 'Formosa' fruits were subjected to the following treatments by immersion: 1 - control (distilled water); 2 - control - fungicide prochloraz (Sportak ${ }^{\circledR} 450$ EC) at a concentration of $0.75 \mathrm{~mL} \mathrm{~L}^{-1} ; 3$ - chitosan (4\%); 4 - aqueous extract of clove (10\%); 5 - aqueous extract of cinnamon (30\%); 6 - aqueous extract of clove $(10 \%)+$ chitosan $(4 \%) ; 7$ - aqueous extract of cinnamon $(30 \%)+$ chitosan (4\%). After 24h, fruits were inoculated with C. gloeosporiodes and evaluated for the disease severity at every two days. Only in the third evaluation, treatments with fungicide and aqueous extract of cinnamon at $30 \%$ associated with chitosan at $4 \%$ reduced the disease severity, compared to control. The area under the disease progress curve indicated that the treatment with aqueous extract of clove was also effective in reducing the severity of anthracnose in fruits.
\end{abstract}

Keywords: Carica papaya L., Colletotrichum gloeosporioides, alternative control. 
A agricultura moderna busca produzir com quantidade, qualidade e preços competitivos, entretanto, as perdas pós-colheita são um grande problema enfrentado pelos produtores de frutas e hortaliças. Estima-se que o desperdício desses produtos seja de 30\% no modelo atual de desenvolvimento agrícola no Brasil (29). Essas perdas são em decorrência de vários fatores, como, por exemplo: colheita e transporte inadequados, falta de beneficiamento e classificação dos frutos, ausência de armazenamento refrigerado, de práticas adequadas de embalagens e de tratamentos auxiliares como a utilização de reguladores de maturação, e de controle de pragas e doenças, entre outros (6).

O mamão (Carica papaya L.) é uma espécie pertencente à família Caricaceae, amplamente cultivado em todo o mundo e em quase todo o território brasileiro, sendo a Bahia o maior estado produtor seguido pelo Espírito Santo. A produção brasileira de mamão, em 2017, foi de 1,057 milhões de toneladas, produzidas em 26,7 mil hectares, e produtividade chegou a 39,8 toneladas por hectare (16).

A cultura do mamão apresenta crescimento significativo no Brasil, tendo como grande desafio a produção de frutos com qualidade póscolheita (29). O padrão de amadurecimento climatérico dos frutos causa perdas naturais na pós-colheita, além disso, as injúrias causadas pelo manuseio inadequado durante a colheita podem acelerar o processo de maturação e servir de porta de entrada para microrganismos fitopatogênicos e, na maioria dos casos, as doenças da pós-colheita são originadas ainda no campo, na fase de produção dos frutos (10), com inóculo permanecendo no fruto até as fases finais da pós-colheita (19).

A comercialização dos frutos de mamoeiro é afetada pela ocorrência de doenças fúngicas como a antracnose, causada por Colletotrichum gloeosporioides (Penz). A podridão causada por esse patógeno pode levar a perda total da produção (8). Essa é considerada a mais importante das doenças pós-colheita e ocorre em todos os países produtores, podendo se manifestar em todos os estádios de desenvolvimento, mas preferencialmente nos frutos maduros (32).

O controle das doenças pós-colheita, na cultura do mamão, é feito por meio do tratamento hidrotérmico e apresenta alta eficiência, porém não tem efeito residual, e preconiza-se a aplicação, em sequência, de ceras fungicidas para prevenir infecções futuras, e reduzir os danos causados pela antracnose (1).

O uso de fungicidas, em curto prazo, foi eficaz para o alcance de grandes produtividades mas, em longo prazo, contribuíram para o surgimento de isolados de fitopatógenos resistentes a essas substâncias químicas, e também são um risco para o meio ambiente e a saúde humana por causa de seus resíduos (25). A ANVISA (2) proibiu o uso do ingrediente ativo procloraz, um dos agroquímicos recomendados para o controle da doença, após uma reavaliação toxicológica concluir que este produto pode causar distúrbios hormonais e danos ao aparelho reprodutor humano.

Este fato aumenta o interesse pela busca de substitutos para os produtos químicos, e a utilização de plantas com potencial antimicrobiano é uma alternativa de interesse econômico e ecológico bastante promissor (26). A identificação de plantas e de seus metabólitos secundários capazes de controlar o desenvolvimento de fitopatógenos ou de induzir resistência nas plantas pode contribuir para aquisição de conhecimentos que reforçam a possível utilização de extratos e óleos vegetais como método de controle alternativo (25).

A eficácia de extratos vegetais e de moléculas naturais no controle de patógenos causadores de doenças pós-colheita in vitro já foi objetivo de muitas pesquisas, entretanto há pouca informação quanto ao seu efeito in vivo (21). Necessita-se de pesquisas visando elucidar o modo de ação dos extratos vegetais e óleos essenciais e também sua aplicabilidade, para que se possa definir sua utilização de modo eficiente para cada fitopatógeno e cultura.

Perante este fato, têm-se buscado por métodos alternativos que sejam viáveis no controle de doenças pós-colheita. Além do armazenamento refrigerado dos frutos, que já é uma prática conhecida pelos seus benefícios no retardo do processo de senescência e redução do ataque de patógenos, e do tratamento hidrotérmico associado a controle químico, a utilização de coberturas comestíveis, como a quitosana e extratos vegetais de diversas plantas mostra-se uma alternativa promissora. Sendo assim, o objetivo deste trabalho foi avaliar a eficácia da quitosana em associação com extratos vegetais de cravo-da-índia (Syzygium aromaticum) e canela (Cinnamomum zeylanicum) na redução do crescimento micelial do C. gloeosporioides in vitro, e na redução da severidade da antracnose em frutos de mamoeiro Formosa.

\section{MATERIAL E MÉTODOS}

Obtenção dos isolados de Colletotrichum gloeosporioides

Os frutos de mamoeiro Formosa com sintomas de antracnose foram lavados em água corrente e secos ao natural. Foram coletados fragmentos da região de transição da lesão e de tecido sadio e, em seguida, lavados em solução de hipoclorito $5 \%$, etanol $70 \%$ e água esterilizada, nessa ordem. Após a secagem em papel filtro esterilizado, os fragmentos foram depositados em placas de Petri com meio de cultivo batata-dextrose-ágar (BDA) e, em seguida, levados a incubadora do tipo BOD, a $25 \pm 2{ }^{\circ} \mathrm{C}$, com alternância luminosa ( $12 \mathrm{~h}$ claro/ $12 \mathrm{~h}$ escuro). Após o crescimento dos isolados, foram feitas repicagens consecutivas até a obtenção de culturas puras. A confirmação da identificação do fungo foi realizada com base em suas características morfológicas (30).

Extratos vegetais e quitosana na inibição do crescimento micelial de Colletotrichum gloeosporioides Penz

$\mathrm{O}$ ensaio foi conduzido em delineamento inteiramente casualizado, em esquema fatorial 7 (tratamentos) x 6 (avaliações), com oito repetições, sendo os tratamentos: $\mathbf{1}$ - testemunha (sem adição de produto ao meio de cultura); 2 - testemunha com fungicida procloraz, (Sportak ${ }^{\circledR}$ 450 EC) na concentração de $100 \mathrm{mg} \mathrm{L}^{-1}$ do ingrediente ativo; $\mathbf{3}$ - extrato aquoso de cravo-da-índia a $15 \% ; 4$ - extrato aquoso de canela a $15 \%$; 5 - quitosana (4\%); 6 - extrato aquoso de cravo-da-índia (15\%)+ quitosana (4\%); 7 - extrato aquoso de canela $(15 \%)+$ quitosana $(4 \%)$.

Para o preparo dos extratos aquosos foi utilizado casca de canela e o botão floral do cravo-da-índia. Para ambos os casos, $30 \mathrm{~g}$ de material vegetal foram triturados em $120 \mathrm{~mL}$ de água destilada por $1 \mathrm{~min}$. Após a trituração, o material foi filtrado em peneira, gaze e algodão, acondicionado em erlenmeyer e deixado em banho-maria a $65^{\circ} \mathrm{C}$ por 60 minutos, a fim de descontaminar a solução.

A solução de quitosana a $4 \%$ foi preparada pela dissolução de $4,0 \mathrm{~g}$ de quitosana em $100 \mathrm{~mL}$ de água destilada com $2 \mathrm{~mL}$ de ácido acético e agitação constante por 24 horas. A solução foi ajustada para $\mathrm{pH} 5,5$, adicionando-se hidróxido de sódio $1 \mathrm{~N}$ e, ao final, $0,1 \mathrm{~mL}$ de Tween 80. A solução de quitosana foi, então, esterilizada em autoclave a $120^{\circ}$ C por 15 minutos (4).

As soluções de extratos, quitosana e fungicida foram adicionadas aos meios de cultura batata-dextrose-ágar (BDA) fundentes, de maneira a se obter as concentrações previamente determinadas, e, após a homogeneização, estes foram vertidos em placas de Petri. Discos de micélio de $0,5 \mathrm{~cm}$ de diâmetro de $C$. gloeosporioides, provenientes de culturas de 12 dias de incubação, foram transferidos para o centro das 
placas de Petri e, em seguida, foram incubadas em câmara BOD a uma temperatura de $25^{\circ} \mathrm{C}$, com fotoperíodo de 12 horas.

As avaliações foram realizadas a cada dois dias, medindo-se o crescimento do diâmetro micelial em dois sentidos, perpendicularmente, até que as colônias das testemunhas atingissem mais de $75 \%$ da placa de Petri.

Os dados de crescimento micelial foram submetidos à análise de variância, as médias foram comparadas pelo teste de Tukey e as médias de períodos de avaliação e sua interação com os outros tratamentos foram ajustadas pela análise de regressão, ambos a $5 \%$ de probabilidade.

\section{Severidade de antracnose em mamão formosa tratado com extratos vegetais e quitosana}

Frutos de mamoeiro Formosa, oriundos da zona rural da região de Dourados-MS, sem tratamento prévio, adotando-se como padrão, frutos em estádio 2 de maturação, segundo a escala utilizada por Ferreguetti (12), foram selecionados, descartando-se aqueles com coloração inadequada ou lesões, a fim de uniformizar o estádio de maturação e o aspecto qualitativo, sem a presença injúrias ou sintomas de doenças. Os frutos foram lavados com água e detergente e secos ao ar para, em seguida, serem submetidos aos tratamentos.

Os mamões foram imersos durante 5 minutos, dois a dois, em solução dos seguintes tratamentos, com posterior secagem natural dos frutos: 1 - Testemunha (imersão em água destilada); 2 - fungicida procloraz (Sportak ${ }^{\circledR} 450 \mathrm{EC}$ ) na concentração de $0,75 \mathrm{~mL}$ do produto comercial para 1 litro de água, por 2 minutos; 3 - quitosana a 4\%; 4 - extrato aquoso de cravo-da-índia a $10 \% ; 5$ - extrato aquoso de canela a $30 \% ; 6$ - extrato aquoso de cravo da índia a $10 \%$ + quitosana a $4 \% ; 7$ - extrato aquoso de canela - extrato aquoso de canela a $30 \%$ + quitosana a $4 \%$. As soluções dos extratos vegetais e de quitosana foram preparadas como descrito, anteriormente, para o ensaio in vitro.

Imediatamente após a imersão dos frutos nos produtos, estes foram apoiados em copos de isopor, com a região peduncular voltada para cima, e envoltos por sacos plásticos, por 24 horas. Ao término deste período, os frutos foram inoculados.

Para inoculação do fungo, foi preparada suspensão de conídios de um isolado de C. gloeosporioides incubado por 12 dias, adicionandose $10 \mathrm{~mL}$ de água destilada esterilizada sobre a superfície da placa de Petri, raspando-a suavemente com alça de Drigalsky. A suspensão foi filtrada em camada dupla de gaze esterilizada e, com auxílio de um hemacitômetro, obtêve-se a concentração de $1,7 \times 10^{5}$ conídios $\mathrm{mL}^{-1}$.

Os frutos foram então perfurados na região peduncular com uma agulha histológica flambada, a profundidade de $2 \mathrm{~cm}$, em quatro locais equidistantes. Sobre a superfície de cada área ferida, foi depositada uma gota (aproximadamente $40 \mu \mathrm{L}$ ) de suspensão de conídios. Para a testemunha, o procedimento foi repetido utilizando-se água destilada esterilizada. Após a inoculação, a região peduncular de cada fruto foi mantida em câmara úmida, utilizando copos de plásticos descartáveis de $50 \mathrm{~mL}$. Estes foram perfurados na base, na qual foi colocada a seção de gaze esterilizado de $5 \mathrm{~cm}^{2}$, umedecida com água destilada esterilizada. O copo foi fixado sobre a região do pedúnculo, com auxílio de fita adesiva na superfície do fruto. A câmara úmida foi desfeita após $48 \mathrm{~h}$ da inoculação, sendo os frutos armazenados em uma câmara a $25^{\circ} \mathrm{C}$, com fotoperíodo de 12 horas $(17,19)$.

As avaliações foram realizadas aos 2, 4 e 6 dias da inoculação, sendo atribuídas notas aos sintomas da podridão peduncular, de acordo com a escala de notas de severidade da doença, sugerida por Nery-Silva et al. (19), em que: 1- Ausência de sintomas da podridão peduncular; 2Presença de pequenas pontuações (até $3 \mathrm{~mm}$ ), aquosas superficiais na região do pedúnculo; 3- Presença de lesões aquosas ou mumificadas, não coalescentes, abrangendo maior área em torno do pedúnculo; 4- Presença de lesões coalescentes, com aspecto translúcido ou mumificado, limitando-se à região peduncular; 5- Lesões semelhantes às descritas na escala 4, abrangendo maior extensão na polpa do fruto, podendo chegar até a cavidade das sementes; o tecido dessa região podendo apresentar excessivo amaciamento.

\section{RESULTADOS E DISCUSSÃO}

\section{Extratos vegetais e quitosana na inibição do crescimento} micelial de $C$. gloeosporioides

O crescimento micelial de C. gloeosporioides foi suprimido pelos tratamentos com extrato aquoso de cravo-da-índia (15\%), extrato aquoso de cravo (15\%) + quitosana (4\%) e com o fungicida procloraz. Ocorreu crescimento micelial nos demais tratamentos, tendo sido maior na testemunha e menores nos tratamentos com canela $(15 \%)+$ quitosana (4\%), seguido de extrato aquoso de canela ( $15 \%$ ) e quitosana (4\%), os quais apresentaram controle semelhante ao longo do período de avaliação (Figura 1).

Estes resultados são complementados na tabela 1, em que se verifica que os tratamentos com fungicida procloraz, extrato aquoso de cravoda-índia a (15\%) e a associação do extrato aquoso de cravo-da-índia a (15\%) com a quitosana a (4\%) foram mais eficientes em relação aos demais tratamentos, principalmente a partir do oitavo dia de incubação. O tratamento com canela $(15 \%)+$ quitosana $(4 \%)$ apresentou efíciência intermediária, diferindo significativamente dos tratamentos mais eficazes, somente a partir do oitavo dia de avaliação. A associação do extrato aquoso de canela (15\%) com a quitosana (4\%) foi mais eficaz do que cada um dos tratamentos isolados, apresentando diferenças significativas nas avaliações realizadas dos 4 aos 8 dias (Tabela 1).

Resultados semelhantes foram obtidos por Rozwalka et al. (24) que, avaliando o efeito fungitóxico de plantas medicinais e aromáticas no crescimento micelial de Glomerella cingulata (C. gloeosporioides), verificaram que o extrato aquoso de cravo-da-índia (10\%) inibiu totalmente o crescimento do patógeno, e em ensaio prévio foi igualmente eficaz na concentração de $1 \%$.

Venturoso et al. (31) não verificaram crescimento de Colletotrichum sp. in vitro, até os 15 dias de avaliação, utilizando extrato aquoso de cravo-da-índia (20\%). Reis et al. (22) também não observaram desenvolvimento do C. gloeosporioides, isolado de mamão, na concentração de extrato aquoso de cravo-da-índia a $15 \%$.

Segundo Costa et al. (7), os componentes majoritários do cravo-daíndia são o eugenol (83,6\%); acetato de eugenila (11,6\%) e cariofileno $(4,2 \%)$. Estes componentes promovem a inibição do crescimento micelial, como também alterações morfológicas no micélio de fungos, intensa fragmentação e menor turgidez das hifas, desorganização dos conteúdos celulares e degradação da parede celular $(7,33)$.

A quitosana mostrou-se eficiente somente quando associada ao extrato de cravo-da-índia a $15 \%$. Reis (21) realizou dois experimentos com quitosana, na concentração de 1 e 3\%, e obteve resultados distintos para o crescimento micelial in vitro em cada um dos testes. No primeiro experimento, a quitosana apresentou efeito intermediário e no segundo inibiu completamente o desenvolvimento do C. gloeosporioides. O autor justifica as divergências de resultados pelo fato dos isolados do patógeno utilizados não terem sido os mesmos para os dois experimentos.

A ação fungitóxica da quitosana é relatada por diversos autores e pode ser explicada devido a desorganização das estruturas celulares 


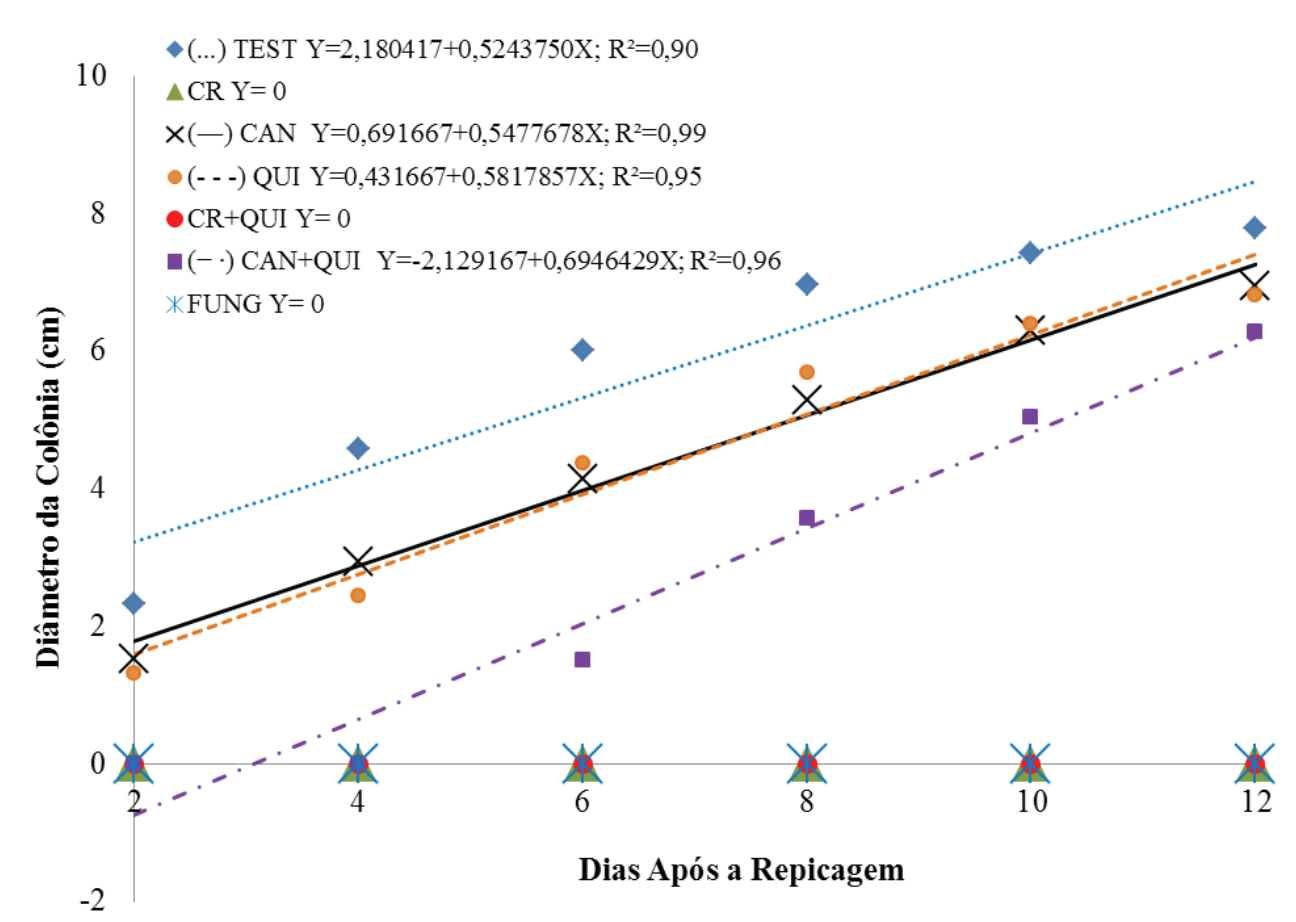

Figura 1. Diâmetro médio de colônias (cm) de Colletotrichum gloeosporioides, sob diferentes tratamentos: Testemunha (TEST), extrato aquoso de cravo-da-índia 15\% (CR), extrato aquoso de canela 15\% (CAN), quitosana 4\% (QUI), extrato aquoso de cravo-da-índia 15\% + quitosana 4\% (CR+QUI), extrato aquoso de canela 15\% + quitosana 4\% (CAN+QUI) e fungicida procloraz $100 \mathrm{mg} \mathrm{L}^{-1}$ (FUNG). Dourados-MS, UFGD, 2015.

Tabela 1. Diâmetro médio de colônias ( $\mathrm{cm}$ ) de Colletotrichum gloeosporioides, in vitro, sob diferentes tratamentos: extrato aquoso de cravo-daíndia $15 \%$, extrato aquoso de canela $15 \%$, quitosana $4 \%$, extrato aquoso de cravo-da-índia $15 \%+$ quitosana $4 \%$, extrato aquoso de canela $15 \%+$ quitosana 4\%, fungicida procloraz e testemunha. Dourados-MS, UFGD, 2015

\begin{tabular}{|c|c|c|c|c|c|c|}
\hline \multirow{2}{*}{ Tratamentos } & \multicolumn{6}{|c|}{ Dias Após Repicagem } \\
\hline & Dia 2 & Dia 4 & Dia 6 & Dia 8 & Dia 10 & Dia 12 \\
\hline Cravo $15 \%$ & b 0,0 & c 0,0 & c 0,0 & $\mathrm{~d} 0,0$ & c 0,0 & b 0,0 \\
\hline Canela $15 \%$ & $\mathrm{ab} 1,5$ & b 2,9 & b 4,1 & b 5,3 & $6,3 \mathrm{ab}$ & a 6,9 \\
\hline Quitosana 4\% & $\mathrm{ab} 1,3$ & b 2,4 & b 4,4 & $\mathrm{ab} 5,7$ & $\mathrm{ab} 6,4$ & a 6,8 \\
\hline Cravo 15\% + Quitosana 4\% & b 0,0 & c 0,0 & c 0,0 & $\mathrm{~d} 0,0$ & c 0,0 & b 0,0 \\
\hline Canela $15 \%$ + Quitosana $4 \%$ & b 0,0 & c 0,0 & c 1,5 & c 3,6 & b 5,0 & a 6,3 \\
\hline Procloraz $100 \mathrm{mg} \mathrm{L}^{-1}$ & b 0,0 & c 0,0 & c 0,0 & $\mathrm{~d} 0,0$ & c 0,2 & b 0,2 \\
\hline Testemunha & a 2,3 & a 4,6 & a 6,0 & a 6,9 & a 7,4 & a 7,8 \\
\hline $\mathbf{C V}=43,1 \%$ & & & & & & \\
\hline
\end{tabular}

Médias seguidas pela mesma letra na coluna, não diferem estatisticamente entre si pelo teste de Tukey a $5 \%$ de probabilidade.

do Colletotrichum sp. causada pela ligação entre as cargas positivas da quitosana e os sítios negativos da parede celular e das membranas celulares, que pode levar as mudanças de permeabilidade e até a morte celular (3).

Cechim (5), ao avaliar diferentes concentrações de quitosana no crescimento micelial in vitro, de Colletotrichum sp., observou que soluções nas concentrações de 0,25 e $0,5 \%$ suprimiram o crescimento micelial após $48 \mathrm{~h}$.

Como era esperado, o fungicida procloraz suprimiu o crescimento micelial do C. gloeosporioides, o que corrobora com os resultados de outros autores $(22,23,28)$.

Severidade de antracnose em mamão formosa tratado com

\section{extratos vegetais e quitosana}

A severidade da antracnose em frutos de mamoeiro foi afetada pelos diferentes tratamentos testados (Tabela 2). Nas avaliações in vivo, não houve diferença significativa entre os tratamentos no segundo e quarto dias de avaliação. Entretanto, no sexto dia após a inoculação, os frutos tratados com fungicida e o tratamento com canela $(30 \%)+$ quitosana (4\%) apresentaram menor severidade nas lesões causadas pelo $C$. gloesporioides com médias significativamente inferiores à testemunha. Considerando-se a área abaixo da curva de progresso da doença, os tratamentos com extrato aquoso de cravo-da-índia a (10\%), de canela a $(30 \%)+$ quitosana a $(4 \%)$ e o fungicida procloraz na concentração $0,75 \mathrm{~mL} \mathrm{~L}^{-1}$ reduziram a severidade da doença. 
Tabela 2. Severidade de antracnose causada pelo Colletotrichum gloeosporioides, em frutos de mamão, sob diferentes tratamentos: extrato aquoso de cravo-da-índia (10\%), extrato aquoso de canela (30\%), extrato aquoso de cravo-da-índia (10\%) + quitosana (4\%), extrato aquoso de canela (30\%) + quitosana (4\%), quitosana (4\%), fungicida procloraz $\left(0,75 \mathrm{~mL} \mathrm{~L}^{-1}\right)$ e testemunha aos 2, 4 e 6 dias após a inoculação. Dourados - MS, UFGD, 2015

\begin{tabular}{|c|c|c|c|c|}
\hline \multirow{2}{*}{ Tratamento } & \multicolumn{3}{|c|}{ Dias Após Inoculação } & \multirow{2}{*}{ AACPD } \\
\hline & 2 & 4 & 6 & \\
\hline Cravo $10 \%$ & $1,25 * \mathrm{a}$ & $2,00 \mathrm{a}$ & $2,75 \mathrm{~b}$ & $8,00 \mathrm{a}$ \\
\hline Canela $30 \%$ & $1,75 \mathrm{a}$ & $2,50 \mathrm{a}$ & $3,50 \mathrm{~b}$ & $10,25 \mathrm{~b}$ \\
\hline Cravo 10\% + Quitosana 4\% & $1,50 \mathrm{a}$ & $2,50 \mathrm{a}$ & $3,25 \mathrm{~b}$ & $9,75 \mathrm{~b}$ \\
\hline Canela 30\% + Quitosana 4\% & $1,50 \mathrm{a}$ & $1,75 \mathrm{a}$ & $2,25 \mathrm{a}$ & $7,25 \mathrm{a}$ \\
\hline Quitosana 4\% & $1,75 \mathrm{a}$ & $2,75 \mathrm{a}$ & $3,50 \mathrm{~b}$ & $10,75 \mathrm{~b}$ \\
\hline Fungicida procloraz & $1,00 \mathrm{a}$ & $1,25 \mathrm{a}$ & $1,50 \mathrm{a}$ & $5,00 \mathrm{a}$ \\
\hline Testemunha & $1,75 \mathrm{a}$ & $2,25 \mathrm{a}$ & $3,25 \mathrm{~b}$ & $9,50 \mathrm{~b}$ \\
\hline CV \% & 30,28 & 30,83 & 22,05 & 24,28 \\
\hline
\end{tabular}

Médias seguidas da mesma letra na coluna não diferem entre si pelo teste de Scott-Knott a 5\% de probabilidade. * Notas de 1 a 5

Em estudo realizado por Fischer et al. (13), a quitosana, em concentrações mais elevadas (10 e 60\%), também, não foi eficaz na redução da incidência da antracnose, causada pelo C. gloeosporioides, em frutos de goiabeira. Já, outros trabalhos, é relatada sua eficência: em pimenta (15), na concentração de 3,5 a 7\%; em morango, pêssego e maçã (5); e em mamão Formosa na concentração de $8 \%$ (22).

Existem evidências de que a quitosana pode atuar de modos distintos em sua ação antimicrobiana, inibindo várias enzimas, alterando a permeabilidade de membranas, o que leva a perda de eletrólitos e constituintes proteicos celulares, e ativando mecanismos de defesa nos tecidos do hospedeiro (9). A capacidade elicitora da quitosana foi verificada por Dousseau et al. (11), ao constatarem em plantas de jaborandi que as enzimas antioxidativas são requisitadas em resposta a aplicação exógena de quitosana, compondo, assim, o mecanismo de defesa dessas plantas.

Em trabalho semelhante, Reis et al. (22) verificaram redução na severidade de antracnose em frutos de mamoeiro 'Formosa' tratados com extrato aquoso de cravo-da-índia na concentração de $15 \%$. Trabalhos que avaliaram o efeito do óleo essencial do cravo-da-índia mostraram sua eficácia como, por exemplo, na redução do diâmetro da lesão causada por C. gloeosporioides em mamão 'Golden', na concentração de $3 \%$, após seis dias da inoculação (14). O composto secundário eugenol está presente tanto no óleo como extrato aquoso, e esses resultados apontam o potencial antimicrobiano do cravo-da-índia para o controle de diversos patógenos em diferentes espécies de plantas.

O extrato aquoso de canela $(30 \%)$ proporcionou redução na severidade da antracnose apenas quando associado à quitosana a $4 \%$, assim como foi observado no experimento in vitro com as mesmas concentrações (Figura 1), o que demonstra efeito sinérgico entre esses dois produtos naturais, potencializando suas ações fungitóxicas.

A eficácia da canela em controlar fitopatógenos é relatada por outros autores. Em concentrações maiores do que neste experimento, de $60 \mathrm{e}$ $80 \%$, houve redução na severidade da podridão por lasiodiplodia em maracujazeiro amarelo (27).

A divergência nos resultados nas diversas alternativas testadas tem sido relatada em diferentes frutíferas, épocas de aplicação e concentração dos produtos. Para cada patossistema, a resposta desses produtos no controle de doenças pós-colheita pode acontecer de forma diferente (20). Além desses fatores, a forma de aproveitamento do material vegetal (seco ou fresco), os métodos de extração, bem como as concentrações utilizadas, podem resultar em maior eficiência e reprodutibilidade dos resultados (31).

O controle da antracnose em mamão Formosa apresentado pelo fungicida procloraz também foi descrito por outros autores: a partir do quarto dia após inoculação, na concentração de $0,75 \mathrm{~mL} \mathrm{~L}^{-1}$, em frutos de mamoeiro 'Formosa' (21); e nas concentrações de 250 e 350 mg do i.a $L^{-1}(18)$.

Os extratos vegetais de cravo-da-índia, canela e a quitosana devem continuar a ser estudados, pois se mostram alternativas viáveis no controle do Colletotrichum gloeosporioides em frutos de mamoeiro.

\section{AGRADECIMENTOS}

À CAPES, pela bolsa concedida, e à Universidade Federal da Grande Dourados - Programa de Pós-Graduação em Agronomia, pelo suporte experimental.

\section{REFERÊNCIAS}

1. Alvarez, A.M.; Nishijima, W.T. Postharvest diseases of papaya. Plant Disease, Saint Paul, v.71, n.7, p.681-686, 1987.

2. ANVISA. Resolução RDC n. 60, de 3 de fevereiro de 2016. Dispõe sobre a proibição da utilização do ingrediente ativo procloraz em produtos agrotóxicos, em decorrência de sua reavaliação toxicológica. Diário Oficial da União, Brasília, 4 de fev. de 2016. Disponível online em: <http://pesquisa.in.gov.br/imprensa/jsp/visualiza/index.jsp?jornal=1\&pagina $=48 \&$ data $=04 / 02 / 2016>$ Acesso em 06 de março de 2016.

3. Assis, O.B.G. The effect of chitosan as a fungistatic agent on cut apples Revista Iberoamericana Tecnología Postcosecha, México, v. 9, n. 2, p. 148-152, 2008.

4. Bautista-Baños, S.; hernández-Lauzardo, A.N.; Velázquez-Delvalle, M.G.; Hernández-López, M.; Barka, E.A.; Bosquez-Molina, E.; Wilson, C.L. Chitosan as a potencial natural compound to control pre and postharvest diseases of horticultural commodities. Crop Protection, Amsterdam, v. 25, n. 2, p. 108-118, 2006.

5. Cechim, F.E. Quitosana na indução de resistência e controle in vitro de mofo cinzento, podridão parda e podridão amarga. 2014. $97 \mathrm{f}$. Tese (Doutorado em Agronomia), Programa de Pós-Graduação em Agronomia (Área de Concentração: Produção vegetal) - Universidade Tecnológica Federal do Paraná. Pato Branco.

6. Chitarra, M.I.F.; Chitarra, A.B. Pós-colheita de frutas e hortaliças: fisiologia e manuseio. $2^{a}$ edição revisada e ampliada. Lavras: UFLA, 785 p. 2005.

7. Costa, A.R.T.; Amaral, M.F.Z.J.; Martins, P.M.; Paula, J.A.M.; Fiuza, T.S.; Tresvenzol, L.M.F.; Paula, J.R.; Bara, M.T.F. Ação do óleo essencial de 
Syzygium aromaticum (L.) Merr. \& L. M. Perry sobre as hifas de alguns fungos fitopatogênicos. Revista Brasileira de Plantas Medicinais, Paulínia, v.13, n.2, p.240-245, 2011

8. Dantas, S.A.F. Doenças fúngicas pós-colheita em frutas de mamão e laranja: ocorrência e indução de resistência com elicitores bióticos e abióticos. 2003. 88 f. Tese (Doutorado em Fitopatologia) - Universidade Federal Rural de Pernambuco, Recife.

9. Devlieghere, F.; Vermeulen, A.; Debevere, J. Chitosan: antimicrobial activity, interactions with food components and applicability as a coating on fruit and vegetables. Food Microbiology, Londres, v. 21, n.6, p. 703-714, 2004.

10. Dickman, M.B.; Alvarez, A.M. Latente infection of papaya caused by Colletotrichum gloeosporioides. Plant Disease, Saint Paul, v. 67, n. 7, p. 748-750, 1983.

11. Dousseau, S; Rodrigues, A.C.; Lira, J.M.S; Ribeiro Júnior, P.M.; Pacheco, F.V.; Alvarenta, A.A; Resende, M.L.V.; De Paula, A.C.C.F.F. Aplicação exógena de quitosana no sistema antioxidante de jaborandi. Revista Ciência Rural, Santa Maria, v.46, n.1, p.191-197, 2016.

12. Ferreguetti, G. Produção de mamão para o mercado externo e interno. Campo Grande: Caliman Agrícola SA, 2006. 1CD-ROM.

13. Fischer, I.H.; Silva, B.L. Da; Soares, A.R.; Arruda, M.C. De; Parisi, M.C.M.; Amorim, L. Efeito de fungicidas e produtos alternativos no controle da antracnose e da pinta preta da goiaba. Semina: Ciências Agrárias, Londrina, v. 33, supl. 1, p. 2753-2766, 2012.

14. Gomes, L.I.S. Métodos de inoculação de Colletotrichum gloeosporioides e efeito dos óleos essenciais no controle da antracnose em frutos de mamoeiro. 2008. 67f. Dissertação (Mestrado em Fitopatologia) - Universidade Federal de Lavras, Lavras.

15. Gomes, E.C.; Serra, I.M.R.S. Eficiência de produtos naturais no controle de Colletotrichum gloeosporioides em pimenta na pós-colheita. Botucatu, Summa Phytopathologica, Botucatu, v.39, n.4, p.290-292, 2013.

16. IBGE - Instituto Brasileiro de Geografia e Estatística. Produção Agrícola Municipal: culturas permanentes. 2017. Disponível online em: $<$ https:// sidra.ibge.gov.br/tabela/1613 >. Acesso em: 12 de dezembro de 2018.

17. Nascimento, L.C.; Nery, A.R.; Rodrigues, L.N. Controle de Colletotrichum gloeosporioides em mamoeiro, utilizando extratos vegetais, indutores de resistência e fungicida. Acta Scientiarum Agronomy, Maringá, v.30, n.3, p.313-319, 2008.

18. Nery-Silva, F.A; Machado, J.C; Lima, L.C.O.; Resende, M.L.V. Controle químico da podridão peduncular de mamão causada por Colletotrichum gloeosporioides. Ciência e Agrotecnologia, Lavras v.25, n.3, p.519-524, 2001.

19. Nery-Silva, F.A., Machado da C.J., Resende de M.L.V., Metodologia de inoculação de fungos causadores da podridão peduncular em Mamão. Ciência e Agrotecnologia, Lavras, v. 31, n. 5, p. 1374-1379, set./out., 2007.

20. Oliveira, S.M.A.; Dantas, S.A.F.; Gurgel, L.M.S. Indução de resistência em doenças pós-colheita em frutas e hortaliças. Revisão Anual de Patologia de Plantas, São Paulo, v. 12, p. 343-371, 2004.
21. Reis, H.F dos. Conservação pós-colheita de mamão formosa (Carica papaya L.) e controle alternativo in vitro e in vivo de Colletotrichum gloeosporioides. 2014. 128 f Tese (Doutorado em Agronomia). Universidade Federal da Grande Dourados, Dourados-MS.

22. Reis, H.F. dos; Bacchi, L.M.A.; Scalon, S.P.Q.; Flores, J.K.P. In vitro antimicrobial activity and alternative control of anthracnose in papaya. Arquivos do Intituto Biológico, São Paulo, v.85, e0192018, p. 1-8, 2018.

23. Rondón, O.; Albarracín, N.S.; Rondón, A. Respuesta in vitro a la acción de fungicidas para el control de antracnosis, Colletotrichum gloeosporioides Penz, en frutos de mango. Agronomia Tropical, Maracay, v.56, n.2, p.219-235, 2006.

24. Rozwalka, L.C.; Lima, M.R.L.Z.C.; Mio, L.L.M.; Nakashima, T. Extratos, decoctos e óleos essenciais de plantas medicinais e aromáticas na inibição de Glomerella cingulata e Colletotrichum gloeosporioides de frutos de goiaba. Ciência Rural, Santa Maria, v.38, n.2, p.301-307, 2008.

25. Schwan-Estrada, K.R.F.; Stangarlin, J.R.; Cruz, M.E.S. Uso de extratos vegetais no controle de fungos fitopatogênicos. Revista Floresta, Curitiba, v.30, n. 1, p.129-37, 2000.

26. Souza, A.E. F.; Araújo, E.; Nascimento, L.C. Atividade antifúngica de extratos de alho e capim-santo sobre o desenvolvimento de Fusarium proliferatum isolado de grãos de milho. Fitopatologia Brasileira, Viçosa, v.32, n.6, p.465-471, 2007.

27. Silva, E.K.C. Condições favoráveis para ocorrência da podridão por lasiodiplodia e métodos alternativos de controle na pós-colheita do maracujá-amarelo. 2012. 95f. Tese (Doutorado em Fitopatologia) - Universidade Federal Rural de Pernambuco, Recife -PE.

28. Tavares, G.M.; Souza, P.E. Efeito de fungicidas no controle in vitro de Colletotrichum gloeosporioides, agente etiológico da antracnose do mamoeiro (Carica papaya L.). Ciência e Agrotecnologia, Lavras, v.29, n.1, p.52-59, 2005.

29. Teodosio, A.E.M.M. Qualidade pós colheita do mamão “Golden” (Carica papaya L.) utilizando recobrimentos biodegradáveis. 2014. 50f. Trabalho de conclusão de curso - Curso de Tecnologia de Alimentos - Universidade Federal da Paraíba, João Pessoa.

30. Torres-Calzada, C.; Tapia-Tussell, R.; Higuera-Ciapara, I.; Perez-Brito, D. Morphological, pathological and genetic diversity of Colletotrichum species responsible for anthracnose in papaya (Carica papaya L.). European Journal of Plant Pathology, Sochi, v.135, n.1, p.67-79, 2012.

31. Venturoso, L.R.; Bacchi, L.M.A.; Gavassoni, W.L.; Conus, L.A.; Pontim, B.C.A; Souza, F.R. Inibição do crescimento in vitro de fitopatógenos sob Diferentes concentrações de extratos de plantas medicinais. Arquivos do Instituto Biológico, São Paulo, v.78, n.1, p.89-95, 2011.

32. Vidal, J.M; Controle alternativo da antracnose em frutos de mamoeiro e qualidade pós-colheita. 2013. 36f. Trabalho de conclusão de curso (Graduação em Agronomia) - Universidade Federal da Paraíba, João Pessoa.

33. Wang, C.; Zhang, J.; Chen, H.; Fan, Y.; Shi, Z. Antifungal activity of eugenol against Botrytis cinerea. Tropical Plant Pathology, Brasília, v.35, n.3, p.137-143, 2010. 